Review Article

\title{
Mechanisms of Innate Lymphoid Cell and Natural Killer T Cell Activation during Mucosal Inflammation
}

\author{
David Nau, ${ }^{1}$ Nora Altmayer, ${ }^{1}$ and Jochen Mattner ${ }^{1,2}$ \\ ${ }^{1}$ Mikrobiologisches Institut-Klinische Mikrobiologie, Immunologie und Hygiene, Universitätsklinikum Erlangen, \\ Friedrich-Alexander Universität Erlangen-Nürnberg, Wasserturmstraße 3/5, 91054 Erlangen, Germany \\ ${ }^{2}$ Division of Immunobiology, Cincinnati Children's Hospital, Cincinnati, OH 45229, USA \\ Correspondence should be addressed to Jochen Mattner; jochen.mattner@uk-erlangen.de
}

Received 1 February 2014; Accepted 28 April 2014; Published 28 May 2014

Academic Editor: Dipyaman Ganguly

Copyright (C) 2014 David Nau et al. This is an open access article distributed under the Creative Commons Attribution License, which permits unrestricted use, distribution, and reproduction in any medium, provided the original work is properly cited.

\begin{abstract}
Mucosal surfaces in the airways and the gastrointestinal tract are critical for the interactions of the host with its environment. Due to their abundance at mucosal tissue sites and their powerful immunomodulatory capacities, the role of innate lymphoid cells (ILCs) and natural killer T (NKT) cells in the maintenance of mucosal tolerance has recently moved into the focus of attention. While NKT cells as well as ILCs utilize distinct transcription factors for their development and lineage diversification, both cell populations can be further divided into three polarized subpopulations reflecting the distinction into Th1, Th2, and Th17 cells in the adaptive immune system. While bystander activation through cytokines mediates the induction of ILC and NKT cell responses, NKT cells become activated also through the engagement of their canonical T cell receptors (TCRs) by (glyco)lipid antigens (cognate recognition) presented by the atypical MHC I like molecule CD1d on antigen presenting cells (APCs). As both innate lymphocyte populations influence inflammatory responses due to the explosive release of copious amounts of different cytokines, they might represent interesting targets for clinical intervention. Thus, we will provide an outlook on pathways that might be interesting to evaluate in this context.
\end{abstract}

\section{Mucosal Surfaces}

Mucosal surfaces represent large areas in which some key interactions of the host with its environment occur [1]. The airway epithelium, for example, is critical for the $\mathrm{O}_{2}-\mathrm{CO}_{2}$ gas exchange, while the intestinal epithelium is required for the absorption of essential nutrients and vitamins. In contrast, however, intestinal as well as airway epithelial cells provide also a physiological barrier function against harmful substances and microbial pathogens $[2,3]$.

In order to distinguish between harmless and pathogenic triggers and antigens $[4,5]$, the mucosal immune system has evolved specific strategies distinct from its systemic counterpart to maintain tolerance on the one hand and also to mount protective responses on the other [6]. Mucosal epithelial cells, for example, play a key role in host defense by providing both a physical barrier and innate defense mechanisms such as the release of defensins. Dendritic cells (DCs) scavenge the mucosal surfaces for microbial antigens, promote $\mathrm{T}$ cell independent IgA responses by B cells, and also shape the adaptive $\mathrm{T}$ cell response within the mucosa and associated lymphoid tissues [7]. As the cytokine milieu is important for the differentiation of tolerance or inflammation, the abundant presence of specified innate immune cells such as innate lymphoid cells (ILCs) and natural killer T (NKT) cells [8-12] that release copious amounts of different cytokines and chemokines upon activation is critical for the generation of regulatory tolerogenic or inflammatory Th1-, Th2-, and Th17-dominated immune responses. Thus, while both cell populations are critical for the maintenance of mucosal tolerance, ILCs as well as NKT cells have been implicated in the induction of inflammatory and autoimmune diseases $[13,14]$. These two cell populations share conserved polarized effector programs (Figure 1), although the molecular pathways involved in this sublineage differentiation must be also divergent as NKT cells, but not ILCs, for example, express 


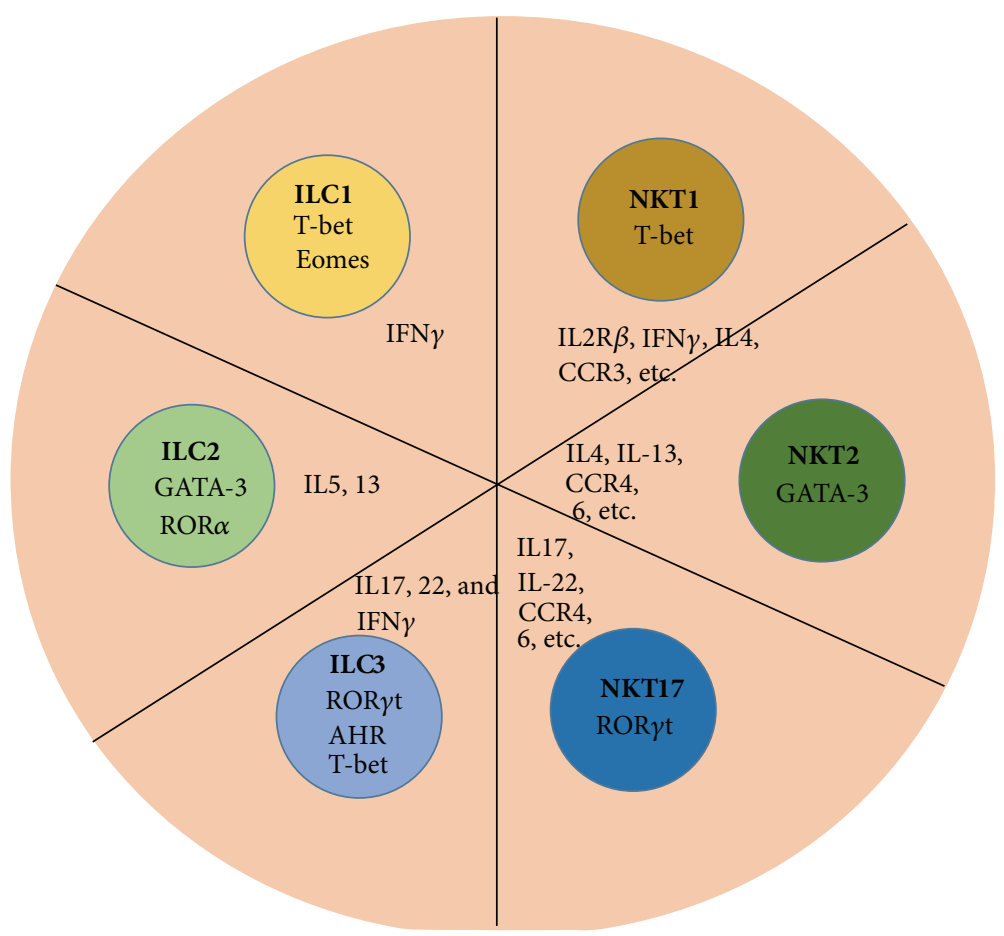

FIGURE 1: Conserved lineage diversification in ILCs and NKT cells. NKT cells as well as ILCs can be divided into three separate sublineages that resemble Th1, Th2, and Th17 subsets in conventional CD4-positive T cells. Group 1 ILCs are characterized by the expression of either T-bet (ILC1) or T-bet and Eomes (NK cells). Group 2 ILCs are defined by the expression of ROR $\alpha$ and GATA3 as well as their ability to release Th2 cytokines. Three sublineages are summarized under the umbrella of group 3 ILCs. While NK cell receptor-negative ILC3s only depend on ROR $\gamma$ t, lymphoid tissue-inducer (LTi) cells require the aryl hydrocarbon receptor (Ahr) in addition to ROR $\gamma$ t. NK cell receptor-expressing ILC3s depend on three transcription factors, AhR, ROR $\gamma$ t and T-bet.

a TCR. Here, we will discuss the mechanisms of activation as well as the capacity of these two cell subsets to modulate inflammatory immune response due to the release of copious amounts of different cytokines.

\section{Development and Differentiation of Innate Lymphoid Cells (ILCs)}

Innate lymphoid cells (ILCs) form a group of developmentally related cells that are characterized through their lymphoid morphology and the absence of RAG-dependent antigen receptors as well as of myeloid and dendritic cell phenotypic markers [15]. Based on functional criteria, cytokine polarization, and transcription factor expression, the six distinct members of the ILC family identified so far can be categorized into groups 1, 2, and 3 ILCs (ILC1, ILC2, and ILC3) [15] (Figure 1). Although the transcriptional repressor Id 2 as well as cytokine signaling through the $\gamma_{3}$ chain of the IL- 2 receptor and the IL-7 receptor are required for the development and/or the maintenance of all of these ILC subsets [16, 17], a common precursor cell despite being widely assumed has not been identified so far [14]. With the exception of natural killer (NK) cells that belong to the ILC1 group and ILC2 that both develop in the bone marrow [18$20]$, the site of generation for the other ILC subsets has not been identified so far.
Although ILCs share developmental similarities, the ILC sublineages express specific transcription factors that drive the generation of each subset individually [21-29]. Those include the signature transcription factors T-bet, GATA-3, and ROR $\gamma \mathrm{t}$ that are also detected in polarized NKT cell sublineages (Figure 1) and differentiated conventional CD4positive T helper cell subsets [30-34]. While group 1 ILCs are characterized by the production of IFN $-\gamma$ and the expression of T-bet (ILC1) or T-bet and Eomes (NK cells), group 2 ILCs are defined by the expression of ROR $\alpha$ and GATA3 as well as their ability to release Th 2 cytokines. In contrast, three sublineages are summarized under the umbrella of group 3 ILCs. While all group 3 ILCs require ROR $\gamma$ t for their development and function and produce IL-17 and IL22 , they are on the one hand distinguished by the expression of NK cell receptors. Lymphoid tissue-inducer (LTi) cells that are essential for the formation of lymph nodes during embryogenesis require the aryl hydrocarbon receptor (Ahr) in addition. In contrast, while $\mathrm{NK}$ cell receptor-negative ILC3s only depend on ROR $\gamma \mathrm{t}$, NK cell receptor-expressing ILC3s require in addition to the AhR also T-bet [15]. However, at least some of the processes underlying this sublineage diversification of ILCs must be different from conventional $\mathrm{T}$ cells and NKT cells despite the similar polarization of cytokine responses, as cognate antigen recognition does not occur in ILCs. The exact molecular mechanisms underlying the generation of the respective ILC subsets and the divergent 
as well as convergent pathways with respect to conventional T cells and NKT cells need to be defined in the future.

\section{Selection of NKT Cells}

NKT cells recognize different (glyco)lipid antigens [35] presented by the atypical MHC I like molecule CD1d on antigenpresenting cells (APCs) [36-38]. While the presentation of endogenous (glyco)lipids is critical for the selection of NKT cells in the thymus [39], NKT cells can survive in the periphery without the presence of CD1d [40]. Although NKT and T cells share similar signaling pathways, the transcription factors driving the development of one or the other lineage are different $[41,42]$. Recently, the promyelocytic leukemia zinc finger PLZF has been defined as the lineage defining transcription factor in NKT cells [43-45]. While the thymic development of NKT cells has been divided into different stages that are characterized by the expression of distinct surface markers and transcription factors, this sequential lineage developmental paradigm for NKT cells was recently challenged by a model describing lineage diversification of NKT cells and simultaneous differentiation into Th1-, Th2-, and Th17-polarized subsets [46]. These polarized sublineages are characterized by the expression of the transcription factors T-bet, GATA-3, and ROR $\gamma \mathrm{t}$ [45], similarly as their conventional CD4-positive $\mathrm{T}$ helper cell counterparts and ILCs (Figure 1). Unlike conventional T cells, however, NKT cells do not require IRF-4 for the production of IL-17 and IL-22 [47]. Despite these distinct discrepancies in the polarization between NKT cells and conventional Th17 cells, the conserved expression pattern of ROR $\gamma$ t, T-bet, and GATA3 in ILCs, NKT cells, and conventional T cells suggest some similarities in the differentiation and cytokine-polarization of all three lineages. Nonetheless, the (molecular) mechanisms underlying this trifurcation of NKT cells are unknown and warrant further investigation.

\section{Activation of ILCs and NKT Cells in the Periphery}

Similarly like NKT cells, ILCs release copious amounts of cytokines upon bystander activation by distinct soluble factors. Those include different Th1, Th2, and Th17 cytokines and also regulatory cytokines such as IL-10, IL-2, or TGF $\beta$. Commensal as well as pathogenic microbes shape thereby the ILC response dependent on the cytokine profile they elicit on intestinal and myeloid cells [48, 49]. While NKT cells similarly like ILCs respond to IL-12, IL-18, IL-1, IL-23, and IL-33 $[14,50]$, only NKT cells, for example, respond to type 1 interferon [51]. Furthermore, the combination of IL- 6 and TGF $\beta$ decreased the CD3/CD28-mediated production of IL22 , but not of IL-17 [52]. DC-derived IL-1 and IL-23 were crucial for the IL-17-production of NKT cells in peripheral lymph nodes [53]. In contrast to NKT cells that can produce Th1 and Th2 simultaneously [54], ILC populations appear to be less plastic and exhibit either Th1-, Th2-, or Th17restricted cytokine profiles $[14,15]$. Furthermore, NKT cells can be also activated through the recognition of (glyco)lipid antigens (cognate activation) by their TCRs. Although NKT cells respond in the periphery to endogenous mammalian and exogenous microbial antigens, CD1d-presented signals are not required for the survival of peripheral NKT cells [55]. Thus, similarly like innate-like $\gamma / \delta \mathrm{T}$ cells, which only need a strong TCR signal for proper development in the thymus [55], NKT cells might not require TCR signals for tissue surveillance in the periphery. However, there exist several microbes in which (glyco)lipid antigens have been detected [56-61] that can activate NKT cells directly through their TCR. Those TCR-activated NKT cells might shape the cellular network different than NKT cells activated through bystander activation by cytokines. The rapid arrest of NKT cells crawling through the liver sinusoids upon (glyco)lipid antigen encounter [62] might reflect one example of altered NKT cells behavior that is not observed when NKT cells react to soluble factors like IL-18 [63]. In addition, NKT cells become anergic for several weeks upon engagement of their TCRs [64]. In contrast, there exist no reports about ILC exhaustion and ILC might continuously release cytokines as long as their activating cytokine receptors such as IL-23R are expressed.

\section{Role of ILCs and NKT Cells in Colitis and Asthma}

Due to their potent immunomodulatory functions and abundance in mucosal tissues, ILCs and NKT cells have been associated with the disruption of mucosal homeostasis in the intestines and airways. Subsets of ILCs, for example, have been implicated in the pathogenesis of colitis [65] and airway inflammation [66-69] due to disturbances in the homeostasis of ILC subsets. While ILC3 cells protected from intestinal pathology, ILC1 subsets promoted mucosal damage. In contrast, predominantly ILC2 subsets were suspected to enhance epithelial damage in the airways due to the release of Th2 cytokines and the augmentation of adaptive Th2 responses. ILC-derived IL-9, a pleiotropic cytokine expressed at elevated levels in the lungs of asthmatic patients $[70,71]$, is thereby critical for the regulation of the Th2-cytokine release. In addition to the apparent pathogenic role of ILC2 cells which release predominantly Th2 cytokines, IL-17 produced by ILC3 subsets promotes airway hypersensitivity, particularly in the context of obesity [72]. Similarly, NKT cells contribute to the induction of pathology in mucosal tissues of the airways and the gastrointestinal tract. Thus, as Th2-polarized NKT cells are predominantly found in the lungs, they accelerate and worsen asthmatic disease $[73,74]$. Comparable to the pathogenic role of ILC2s, NKT cells drive allergic inflammatory reactions through the production of type 2 cytokines and the recruitment and degranulation of mast cells and eosinophils [75, 76]. Similar pathogenic mechanisms might apply for the recruitment of eosinophils by NKT cells at other mucosal tissue sites, such as the esophagus [77]. While NKT cells in asthmatic mouse models induced by OVA are activated preferentially due to bystander activation, 
(glyco)lipid antigens detected in the fungus Aspergillus fumigatus or in cypress pollen drive cognate NKT cell activation and subsequently allergic airway inflammation [78, 79]. The nature of the (glyco)lipid engaging the NKT cell TCR might be thereby critical for the outcome of disease, as the application of alpha-galactosylceramide ( $\alpha$-GalCer), the prototypical NKT cell ligand, has been also associated with suppression of asthmatic immune reactions [80, 81]. However, particularly ILC2s produce also other cytokines, such as IL-25 and IL-33, that are critical for the maintenance of mucosal tolerance $[82,83]$ as well as the TNF family cytokine TLA-1 that promotes pathology [84]. Although the cognate recognition of the prototypical NKT cell ligand $\alpha$-GalCer promoted pathogenic NKT cell responses dependent on the genetic background of the mice and the diseases investigated $[85,86]$, there exists also evidence for strong inflammatory effects on NKT cells through bystander activation, elicited, for example, through the application of poly-IC $[87,88]$. On the other hand, the application of $\alpha$-GalCer can also inhibit or ameliorate autoimmune diseases [89]. Although the processes underlying these inhibitory effects have not been completely resolved, cell-contact dependent interactions as well as the release of anti-inflammatory mediators have been suggested as protective mechanisms, which inhibit the expansion of autoreactive lymphocyte populations. However, while being the source of IL-22 that acts directly on epithelial cells [90], ILCs can also exhibit protective effects in mucosal tissues [91, 92]. A constitutive expression of IL-17 and IL-22 that is critical for the integrity of the intestinal mucosa and maintenance of epithelial homeostasis has been attributed to the ROR $\gamma t$-positive ILC3 subset $[93,94]$. In contrast, Th17-cytokines, IL-13, and IFN- $\gamma$ that are released by ILCs and NKT cells promote instead the pathogenesis of IBD $[14,95,96]$. In this context, there exists strong evidence that particularly IL-17-producing ILC3s as well as IL-23-reactive ILCs drive tissue pathology in IBD [97-100]. Thereby the local cytokine [101] as well as the microbial milieu [102] plays a critical role. In accordance with these studies, the depletion of an IFN- $\gamma$ - and IL-17-producing ILC3 subset inhibited the development of intestinal pathology in a Helicobacter hepaticus-induced colitis model [103]. Furthermore, patients suffering from inflammatory bowel disease (IBD) revealed enhanced numbers of ILCs expressing IL-17 and IL-22 [104]. Th2- and Th17- polarized NKT cells have been implicated in the pathogenesis of colitis as well $[105,106]$. In contrast to ILCs, however, the presence of the intestinal microbiota protected from NKT cell-mediated pathogenic responses in colitis $[107,108]$.

\section{Interactions of NKT Cells and ILCs}

Although sparse up to now, there exists experimental evidence for direct interactions of ILCs and NKT cells. While being target cells for ILC-produced cytokines, NKT cells enhance airway hyperreactivity and trigger lung pathology [109]. IL-25 plays thereby a critical pathogenic role as it promotes the production of IL-13 by nuocytes and NKT cells [110]. Besides allergic lung diseases, one publication reported also a regulation of ILC responses through NKT cells during viral infection [111]. NKT cells as well as alveolar macrophages represented in this model a cellular source for IL-33, which promoted the production of IL- 5 by ILC2 cells. While these studies highlight the interactions of these two powerful innate immune cell populations, further studies need to define whether certain signal patterns can polarize the ILC and NKT cell response in one or the other direction or whether there exists a hierarchy in the interactions of ILC and NKT cell responses. With respect to IBD, certainly also the interactions of distinct components of the intestinal flora with ILCs and NKT cells warrant further investigation.

\section{Summary and Outlook}

ILCs and NKT cells play a critical role in the maintenance of mucosal homeostasis. Not only the various pattern recognition and cytokine receptors engaged but also the different sublineages involved under steady state and pathogenic conditions might shape the subsequent immune response of the complex downstream cellular network and influence the generation of inflammatory versus tolerogenic reactions. Thus, due to their potent immunomodulatory properties and their broad activation during inflammation, autoimmune disease, or infection both cell populations represent not only attractive targets for clinical intervention in the mucosa, but also at other tissue sites such as the liver or spleen. As both cell populations are characterized through polarized effector programs and lineage diversification (Figure 1), which are also known in the adaptive arm of the immune system, distinct common pathways certainly exist. However, although these diversification processes appear to be conserved, the receptors and molecular mechanisms driving this diversification cannot all be shared, for example, due to the involvement of TCR versus cytokine signaling. Although bystander activation induces cytokine responses in both cell populations, interference with cytokine receptors that are abundantly expressed also on other cell populations might elicit too many unspecific side effects. Thus, in order to polarize immune responses, ILCs as well as NKT cell subset specific surface molecules need to be identified and can be specifically targeted.

\section{Conflict of Interests}

The authors declare that there is no conflict of interests regarding the publication of this paper.

\section{Acknowledgments}

This work is supported by Award R01DK084054 from the National Institute of Diabetes and Digestive and Kidney Diseases, by the German Research Foundation Deutsche Forschungsgemeinschaft (MA 2621/2-1 and MA 2621/3-1), and by the Interdisciplinary Center for Clinical Research of the Universitätsklinikum Erlangen (IZKF_JB10_A48). 


\section{References}

[1] B. K. Wershil and G. T. Furuta, "4. Gastrointestinal mucosal immunity," Journal of Allergy and Clinical Immunology, vol. 121, supplement 2, no. 2, pp. S380-S383, 2008.

[2] J. R. Turner, "Intestinal mucosal barrier function in health and disease," Nature Reviews Immunology, vol. 9, no. 11, pp. 799-809, 2009.

[3] A. K. Mayer and A. H. Dalpke, "Regulation of local immunity by airway epithelial cells," Archivum Immunologiae et Therapiae Experimentalis, vol. 55, no. 6, pp. 353-362, 2007.

[4] P. J. Sansonetti, "To be or not to be a pathogen: that is the mucosally relevant question," Mucosal Immunology, vol. 4, no. 1, pp. 8-14, 2011.

[5] L. Steele, L. Mayer, and M. C. Berin, "Mucosal immunology of tolerance and allergy in the gastrointestinal tract," Immunologic Research, vol. 54, no. 1-3, pp. 75-82, 2012.

[6] H. Kayama and K. Takeda, "Regulation of intestinal homeostasis by innate and adaptive immunity," International Immunology, vol. 24, no. 11, pp. 673-680, 2012.

[7] J. R. McGhee and K. Fujihashi, "Inside the mucosal immune system," PLoS Biology, vol. 10, no. 9, Article ID e1001397, 2012.

[8] P. Aparicio-Domingo and T. Cupedo, "Ror $\gamma t+$ innate lymphoid cells in intestinal homeostasis and immunity," Journal of Innate Immunity, vol. 3, no. 6, pp. 577-584, 2011.

[9] J. P. di Santo, C. A. J. Vosshenrich, and N. Satoh-Takayama, "A "natural" way to provide innate mucosal immunity," Current Opinion in Immunology, vol. 22, no. 4, pp. 435-441, 2010.

[10] S. Middendorp and E. E. S. Nieuwenhuis, "NKT cells in mucosal immunity," Mucosal Immunology, vol. 2, no. 5, pp. 393-402, 2009.

[11] J. H. Bernink, C. P. Peters, M. Munneke et al., "Human type 1 innate lymphoid cells accumulate in inflamed mucosal tissues," Nature Immunology, vol. 14, pp. 221-229, 2013.

[12] H. Xu, X. Wang, D. X. Liu, T. Moroney-Rasmussen, A. A. Lackner, and R. S. Veazey, "IL-17-producing innate lymphoid cells are restricted to mucosal tissues and are depleted in SIVinfected macaques," Mucosal Immunology, vol. 5, pp. 658-669, 2012.

[13] S. P. Berzins, M. J. Smyth, and A. G. Baxter, "Presumed guilty: natural killer T cell defects and human disease," Nature Reviews Immunology, vol. 11, no. 2, pp. 131-142, 2011.

[14] J. A. Walker, J. L. Barlow, and A. N. McKenzie, "Innate lymphoid cells-how did we miss them?” Nature Reviews Immunology, vol. 13, pp. 75-87, 2013.

[15] H. Spits, D. Artis, M. Colonna et al., "Innate lymphoid cells-a proposal for uniform nomenclature," Nature Reviews Immunology, vol. 13, pp. 145-149, 2013.

[16] H. Spits and J. P. di Santo, "The expanding family of innate lymphoid cells: regulators and effectors of immunity and tissue remodeling," Nature Immunology, vol. 12, no. 1, pp. 21-27, 2011.

[17] C. Vonarbourg and A. Diefenbach, "Multifaceted roles of interleukin-7 signaling for the development and function of innate lymphoid cells," Seminars Immunology, vol. 24, no. 3, pp. 165-174, 2012.

[18] J. A. Walker and A. N. McKenzie, "Development and function of group 2 innate lymphoid cells," Current Opinion Immunology, vol. 25, no. 2, pp. 148-155, 2013.

[19] C. A. Vosshenrich and J. P. di Santo, "Developmental programming of natural killer and innate lymphoid cells," Current Opinion Immunology, vol. 25, no. 2, pp. 130-138, 2013.
[20] M. Cherrier, C. Ohnmacht, S. Cording, and G. Eberl, "Development and function of intestinal innate lymphoid cells," Current Opinion Immunology, vol. 24, no. 3, pp. 277-283, 2012.

[21] C. Possot, S. Schmutz, S. Chea et al., "Notch signaling is necessary for adult, but not fetal, development of $\operatorname{ROR} \gamma(+)$ innate lymphoid cells," Nature Immunology, vol. 12, no. 10, pp. 949-958, 2011.

[22] M. Cherrier, S. Sawa, and G. Eberl, "Notch, Id2, and ROR $\gamma \mathrm{t}$ sequentially orchestrate the fetal development of lymphoid tissue inducer cells," Journal of Experimental Medicine, vol. 209, no. 4, pp. 729-740, 2012.

[23] J. Mjosberg, J. Bernink, C. Peters, and H. Spits, “Transcriptional control of innate lymphoid cells," European Journal of Immunology, vol. 42, no. 8, pp. 1916-1923, 2012.

[24] Y. O. Ahn, B. R. Blazar, J. S. Miller, and M. R. Verneris, "Lineage relationships of human interleukin-22-producing CD56+ ROR $\gamma \mathrm{t}+$ innate lymphoid cells and conventional natural killer cells," Blood, vol. 121, no. 12, pp. 2234-2243, 2013.

[25] T. Hoyler, C. S. Klose, A. Souabni et al., "The transcription factor GATA-3 controls cell fate and maintenance of type 2 innate lymphoid cells," Immunity, vol. 37, no. 4, pp. 634-648, 2012.

[26] L. Zhou, "Striking similarity: GATA-3 regulates ILC2 and Th2 cells," Immunity, vol. 37, no. 4, pp. 589-591, 2012.

[27] M. Romera-Hernandez, P. Aparicio-Domingo, and T. Cupedo, "Damage control: Ror $\gamma \mathrm{t}+$ innate lymphoid cells in tissue regeneration," Current Opinion Immunology, vol. 25, no. 2, pp. 156160, 2013.

[28] H. Spits and T. Cupedo, "Innate lymphoid cells: emerging insights in development, lineage relationships, and function," Annual Review of Immunology, vol. 30, pp. 647-675, 2012.

[29] S. H. Wong, J. A. Walker, H. E. Jolin et al., "Transcription factor ROR $\alpha$ is critical for nuocyte development," Nature Immunology, vol. 13, pp. 229-236, 2012.

[30] T. R. Mosmann, H. Cherwinski, M. W. Bond, M. A. Giedlin, and R. L. Coffman, "Two types of murine helper T cell clone. I. Definition according to profiles of lymphokine activities and secreted proteins," Journal of Immunology, vol. 136, no. 7, pp. 2348-2357, 1986.

[31] L. Zhou, M. M. W. Chong, and D. R. Littman, "Plasticity of CD4+ T cell lineage differentiation," Immunity, vol. 30, no. 5, pp. 646-655, 2009.

[32] R. M. Locksley, "Nine lives: plasticity among T helper cell subsets," Journal of Experimental Medicine, vol. 206, no. 8, pp. 1643-1646, 2009.

[33] K. M. Murphy and B. Stockinger, "Effector T cell plasticity: flexibility in the face of changing circumstances," Nature Immunology, vol. 11, no. 8, pp. 674-680, 2010.

[34] J. O'Shea and W. E. Paul, "Mechanisms underlying lineage commitment and plasticity of helper CD4+ T cells," Science, vol. 327, no. 5969, pp. 1098-1102, 2010.

[35] J. Mattner, "Natural killer T, (NKT) cells in autoimmune hepatitis," Current Opinion Immunology, vol. 25, no. 6, pp. 697703, 2013.

[36] E. M. Beckman, S. A. Porcelli, C. T. Morita, S. M. Behar, S. T. Furlong, and M. B. Brenner, "Recognition of lipid antigen by CD1-restricted $\alpha \beta+$ T cells," Nature, vol. 372, no. 6507, pp. 691694, 1994.

[37] A. Bendelac, O. Lantz, M. E. Quimby, J. W. Yewdell, J. R. Bennink, and R. R. Brutkiewicz, "CD1 recognition by mouse NK1+ T lymphocytes,” Science, vol. 268, no. 5212, pp. 863-865, 1995. 
[38] T. Kawano, J. Cui, Y. Koezuka et al., "CD1d-restricted and TCRmediated activation of V $\alpha 14$ NKT cells by glycosylceramides," Science, vol. 278, no. 5343, pp. 1626-1629, 1997.

[39] A. Bendelac, P. B. Savage, and L. Teyton, "The biology of NKT cells," Annual Review of Immunology, vol. 25, pp. 297-336, 2007.

[40] D. G. Wei, H. Lee, S.-H. Park et al., "Expansion and long-range differentiation of the NKT cell lineage in mice expressing CD1d exclusively on cortical thymocytes," Journal of Experimental Medicine, vol. 202, no. 2, pp. 239-248, 2005.

[41] R. Das, D. B. Sant'Angelo, and K. E. Nichols, "Transcriptional control of invariant NKT cell development," Immunological Reviews, vol. 238, no. 1, pp. 195-215, 2010.

[42] S. P. Berzins, A. P. Uldrich, D. G. Pellicci et al., "Parallels and distinctions between $\mathrm{T}$ and NKT cell development in the thymus," Immunology and Cell Biology, vol. 82, no. 3, pp. 269275, 2004.

[43] L. Gapin, “The making of NKT cells," Nature Immunology, vol. 9, no. 9, pp. 1009-1011, 2008.

[44] M. Gleimer, H. von Boehmer, and T. Kreslavsky, "PLZF controls the expression of a limited number of genes essential for NKT cell function," Frontiers in Immunology, vol. 3, article 374, 2012.

[45] M. G. Constantinides and A. Bendelac, "Transcriptional regulation of the NKT cell lineage," Current Opinion Immunology, vol. 25, no. 2, pp. 161-167, 2013.

[46] Y. J. Lee, K. L. Holzapfel, J. Zhu, S. C. Jameson, and K. A. Hogquist, "Steady-state production of IL-4 modulates immunity in mouse strains and is determined by lineage diversity of iNKT cells," Nature Immunology, vol. 14, pp. 1146-1154, 2013.

[47] H. Raifer, A.J. Mahiny, and N. Bollig, "Unlike $\alpha \beta \mathrm{T}$ cells, $\gamma \delta \mathrm{T}$ cells, LTi cells and NKT cells do not require IRF4 for the production of IL-17A and IL-22," European Journal of Immunology, vol. 42, no. 12, pp. 3189-3201, 2012.

[48] N. H. Philip and D. Artis, "New friendships and old feuds: relationships between innate lymphoid cells and microbial communities," Immunology and Cell Biology, vol. 91, pp. 225231, 2013.

[49] A. Diefenbach, "Innate lymphoid cells in the defense against infections," European Journal of Microbiology and Immunology, vol. 3, no. 3, pp. 143-151, 2013.

[50] P. J. Brennan, M. Brigl, and M. B. Brenner, "Invariant natural killer T cells: an innate activation scheme linked to diverse effector functions," Nature Reviews Immunology, vol. 13, pp. 101117, 2013.

[51] C. Paget, T. Mallevaey, A. O. Speak et al., "Activation of invariant NKT cells by toll-like receptor 9-stimulated dendritic cells requires type I interferon and charged glycosphingolipids," Immunity, vol. 27, no. 4, pp. 597-609, 2007.

[52] M. Goto, M. Murakawa, K. Kadoshima-Yamaoka et al., "Murine NKT cells produce Th17 cytokine interleukin-22," Cellular Immunology, vol. 254, no. 2, pp. 81-84, 2009.

[53] J.-M. Doisne, V. Soulard, C. Bécourt et al., "Cutting edge: crucial role of IL-1 and IL-23 in the innate IL-17 response of peripheral lymph node NK1.1- invariant NKT cells to bacteria," Journal of Immunology, vol. 186, no. 2, pp. 662-666, 2011.

[54] J. L. Matsuda, L. Gapin, J. L. Baron et al., "Mouse V $\alpha 14$ i natural killer T cells are resistant to cytokine polarization in vivo," Proceedings of the National Academy of Sciences of the United States of America, vol. 100, no. 14, pp. 8395-8400, 2003.

[55] M. Wencker, G. Turchinovich, R. di Marco Barros et al., "Innatelike $\mathrm{T}$ cells straddle innate and adaptive immunity by altering antigen-receptor responsiveness," Nature Immunology, vol. 15, pp. $80-87,2014$.
[56] J. Mattner, K. L. Debord, N. Ismail et al., "Exogenous and endogenous glycolipid antigens activate NKT cells during microbial infections," Nature, vol. 434, no. 7032, pp. 525-529, 2005.

[57] Y. Kinjo, D. Wu, G. Kim et al., "Recognition of bacterial glycosphingolipids by natural killer T cells," Nature, vol. 434, no. 7032, pp. 520-525, 2005.

[58] Y. Kinjo, E. Tupin, D. Wu et al., "Natural killer T cells recognize diacylglycerol antigens from pathogenic bacteria," Nature Immunology, vol. 7, no. 9, pp. 978-986, 2006.

[59] Y. Kinjo, P. Illarionov, J. L. Vela et al., "Invariant natural killer $\mathrm{T}$ cells recognize glycolipids from pathogenic Gram-positive bacteria," Nature Immunology, vol. 12, no. 10, pp. 966-974, 2011.

[60] J. L. Amprey, J. S. Im, S. J. Turco et al., "A subset of liver NK T cells is activated during Leishmania donovani infection by CD1d-bound lipophosphoglycan," Journal of Experimental Medicine, vol. 200, no. 7, pp. 895-904, 2004.

[61] K. Fischer, E. Scotet, M. Niemeyer et al., "Mycobacterial phosphatidylinositol mannoside is a natural antigen for CD1drestricted T cells," Proceedings of the National Academy of Sciences of the United States of America, vol. 101, no. 29, pp. 10685-10690, 2004.

[62] F. Geissmann, T. O. Cameron, S. Sidobre et al., "Intravascular immune surveillance by CXCR6+ NKT cells patrolling liver sinusoids," PLoS Biology, vol. 3, no. 4, article el13, 2005.

[63] P. Velázquez, T. O. Cameron, Y. Kinjo, N. Nagarajan, M. Kronenberg, and M. L. Dustin, "Cutting edge: activation by innate cytokines or microbial antigens can cause arrest of natural killer T cell patrolling of liver sinusoids," Journal of Immunology, vol. 180, no. 4, pp. 2024-2028, 2008.

[64] V. V. Parekh, M. T. Wilson, D. Olivares-Villagómez et al., "Glycolipid antigen induces long-term natural killer $\mathrm{T}$ cell anergy in mice," Journal of Clinical Investigation, vol. 115, no. 9, pp. 2572-2583, 2005.

[65] K. Kimura, T. Kanai, A. Hayashi et al., "Dysregulated balance of retinoid-related orphan receptor $\gamma \mathrm{t}$-dependent innate lymphoid cells is involved in the pathogenesis of chronic DSS-induced colitis," Biochemical and Biophysical Research Communications, vol. 427, pp. 694-700, 2012.

[66] B. W. Li and R. W. Hendriks, "Group 2 innate lymphoid cells in lung inflammation," Immunology, vol. 140, no. 3, pp. 281-287, 2013.

[67] S. T. Scanlon and A. N. McKenzie, "Type 2 innate lymphoid cells: new players in asthma and allergy," Current Opinion Immunology, vol. 24, no. 6, pp. 707-712, 2012.

[68] T. Y. Halim and A. N. McKenzie, "New kids on the block: group 2 innate lymphoid cells and type 2 inflammation in the lung," Chest, vol. 144, pp. 1681-1686, 2013.

[69] J. Deckers, F. Branco Madeira, and H. Hammad, "Innate immune cells in asthma," Trends Immunology, vol. 34, no. 11, pp. 540-547, 2013.

[70] V. J. Erpenbeck, J. M. Hohlfeld, B. Volkmann et al., "Segmental allergen challenge in patients with atopic asthma leads to increased IL-9 expression in bronchoalveolar lavage fluid lymphocytes," Journal of Allergy and Clinical Immunology, vol. 111, no. 6, pp. 1319-1327, 2003.

[71] A. Shimbara, P. Christodoulopoulos, A. Soussi-Gounni et al., "IL-9 and its receptor in allergic and nonallergic lung disease: increased expression in asthma," Journal of Allergy and Clinical Immunology, vol. 105, no. 1 I, pp. 108-115, 2000. 
[72] H. Y. Kim, H. J. Lee, Y. J. Yang et al., "Interleukin-17-producing innate lymphoid cells and the NLRP3 inflammasome facilitate obesity-associated airway hyperreactivity," Nature Medicine, vol. 20, pp. 54-61, 2014.

[73] D. T. Umetsu and R. H. DeKruyff, "Natural killer T cells are important in the pathogenesis of asthma: the many pathways to asthma," Journal of Allergy and Clinical Immunology, vol. 125, no. 5, pp. 975-979, 2010.

[74] C. Iwamura and T. Nakayama, "Role of NKT cells in allergic asthma," Current Opinion in Immunology, vol. 22, no. 6, pp. 807813, 2010.

[75] Y. Minai-Fleminger and F. Levi-Schaffer, "Mast cells and eosinophils: the two key effector cells in allergic inflammation," Inflammation Research, vol. 58, no. 10, pp. 631-638, 2009.

[76] K. Amin, "The role of mast cells in allergic inflammation," Respiratory Medicine, vol. 106, no. 1, pp. 9-14, 2012.

[77] M. Rayapudi, P. Rajavelu, X. Zhu et al., "Invariant natural killer T-cell neutralization is a possible novel therapy for human eosinophilic esophagitis," Clinical and Translational Immunology, vol. 3, article e9, 2014.

[78] L. A. Albacker, V. Chaudhary, Y. J. Chang et al., "Invariant natural killer $\mathrm{T}$ cells recognize a fungal glycosphingolipid that can induce airway hyperreactivity," Nature Medicine, vol. 19, pp. 1297-1304, 2013.

[79] E. Agea, A. Russano, O. Bistoni et al., "Human CD1-restricted T cell recognition of lipids from pollens," Journal of Experimental Medicine, vol. 202, no. 2, pp. 295-308, 2005.

[80] P. Hachem, M. Lisbonne, M.-L. Michel et al., " $\alpha$ galactosylceramide-induced iNKT cells suppress experimental allergic asthma in sensitized mice: role in IFN- $\gamma$," European Journal of Immunology, vol. 35, no. 10, pp. 2793-2802, 2005.

[81] H. Matsuda, T. Suda, J. Sato et al., " $\alpha$-galactosylceramide, a ligand of natural killer T cells, inhibits allergic airway inflammation," The American Journal of Respiratory Cell and Molecular Biology, vol. 33, no. 1, pp. 22-31, 2005.

[82] P. Licona-Limon, L. K. Kim, N. W. Palm, and R. A. Flavell, “TH2, allergy and group 2 innate lymphoid cells," Nature Immunology, vol. 14, pp. 536-542, 2013.

[83] J. L. Barlow, S. Peel, J. Fox et al., "IL-33 is more potent than IL-25 in provoking IL-13-producing nuocytes (type 2 innate lymphoid cells) and airway contraction," Journal of Allergy and Clinical Immunology, vol. 132, no. 4, pp. 933-941, 2013.

[84] F. Meylan, E. T. Hawley, L. Barron et al., "The TNF-family cytokine TL1A promotes allergic immunopathology through group 2 innate lymphoid cells," Mucosal Immunology, 2013.

[85] D. Zeng, Y. Liu, S. Sidobre, M. Kronenberg, and S. Strober, "Activation of natural killer T cells in NZB/W mice induces Th1type immune responses exacerbating lupus," Journal of Clinical Investigation, vol. 112, no. 8, pp. 1211-1222, 2003.

[86] C. Forestier, A. Molano, J. S. Im et al., "Expansion and hyperactivity of CD1d-restricted NKT cells during the progression of systemic lupus erythematosus in (New Zealand Black $\times$ New Zealand White)F1 mice," Journal of Immunology, vol. 175, no. 2, pp. 763-770, 2005.

[87] A. Vultaggio, F. Nencini, S. Pratesi et al., "Poly(I:C) promotes the production of IL-17A by murine CD1d-driven invariant NKT cells in airway inflammation," Allergy, vol. 67, no. 10, pp. 12231232, 2012.

[88] J. P. Choi, Y. M. Kim, H. I. Choi et al., "An important role of tumor necrosis factor receptor-2 on natural killer T cells on the development of dsRNA-enhanced Th2 cell response to inhaled allergens," Allergy, vol. 69, no. 2, pp. 186-198, 2013.
[89] L. Wu and L. van Kaer, "Natural killer T cells and autoimmune disease," Current Molecular Medicine, vol. 9, no. 1, pp. 4-14, 2009.

[90] S. Rutz, C. Eidenschenk, and W. Ouyang, "IL-22, not simply a Th17 cytokine," Immunological Reviews, vol. 252, no. 1, pp. 116132, 2013

[91] C. Taube, C. Tertilt, G. Gyülveszi et al., "IL-22 is produced by innate lymphoid cells and limits inflammation in allergic airway disease," PLoS ONE, vol. 6, no. 7, Article ID e21799, 2011.

[92] H. Li and R. K. Reeves, "Functional perturbation of classical natural killer and innate lymphoid cells in the oral mucosa during SIV infection," Frontiers Immunology, vol. 3, article 417, 2012.

[93] K. Wolk, E. Witte, K. Witte, K. Warszawska, and R. Sabat, "Biology of interleukin-22," Seminars in Immunopathology, vol. 32, no. 1, pp. 17-31, 2010.

[94] S. Sawa, M. Lochner, N. Satoh-Takayama et al., "ROR $\gamma t(+)$ innate lymphoid cells regulate intestinal homeostasis by integrating negative signals from the symbiotic microbiota," Nature Immunology, vol. 12, no. 4, pp. 320-326, 2011.

[95] N. Qu, M. Xu, I. Mizoguchi et al., "Pivotal roles of T-helper 17-related cytokines, IL-17, IL-22, and IL-23, in inflammatory diseases," Clinical and Developmental Immunology, vol. 2013, Article ID 968549, 13 pages, 2013.

[96] I. C. Roberts-Thomson, J. Fon, W. Uylaki, A. G. Cummins, and S. Barry, "Cells, cytokines and inflammatory bowel disease: a clinical perspective," Expert Review of Gastroenterology and Hepatology, vol. 5, no. 6, pp. 703-716, 2011.

[97] T. Kanai, Y. Mikami, T. Sujino, T. Hisamatsu, and T. Hibi, "ROR $\gamma$ t-dependent IL-17A-producing cells in the pathogenesis of intestinal inflammation," Mucosal Immunology, vol. 5, no. 3, pp. 240-247, 2012.

[98] C. E. Sutton, L. A. Mielke, and K. H. Mills, "IL-17-producing $\gamma \delta \mathrm{T}$ cells and innate lymphoid cells," European Journal of Immunology, vol. 42, no. 9, pp. 2221-2231, 2012.

[99] A. Geremia, C. V. Arancibia-Cárcamo, M. P. P. Fleming et al., "IL-23-responsive innate lymphoid cells are increased in inflammatory bowel disease," Journal of Experimental Medicine, vol. 208, no. 6, pp. 1127-1133, 2011.

[100] A. Eken, A. K. Singh, P. M. Treuting, and M. Oukka, "IL$23 \mathrm{R}(+)$ innate lymphoid cells induce colitis via interleukin-22dependent mechanism," Mucosal Immunology, vol. 7, pp. 143154, 2014.

[101] N. Powell, A. W. Walker, E. Stolarczyk et al., “The transcription factor T-bet regulates intestinal inflammation mediated by interleukin-7 receptor+ innate lymphoid cells," Immunity, vol. 37, no. 4, pp. 674-684, 2012.

[102] J. Behnsen and M. Raffatellu, "Keeping the peace: aryl hydrocarbon receptor signaling modulates the mucosal microbiota," Immunity, vol. 39, no. 2, pp. 206-207, 2013.

[103] S. Buonocore, P. P. Ahern, H. H. Uhlig et al., "Innate lymphoid cells drive interleukin-23-dependent innate intestinal pathology," Nature, vol. 464, no. 7293, pp. 1371-1375, 2010.

[104] A. Geremia, C. V. Arancibia-Cárcamo, M. P. P. Fleming et al., "IL-23-responsive innate lymphoid cells are increased in inflammatory bowel disease," Journal of Experimental Medicine, vol. 208, no. 6, pp. 1127-1133, 2011.

[105] I. J. Fuss and W. Strober, "The role of IL-13 and NK T cells in experimental and human ulcerative colitis," Mucosal Immunology, vol. 1, supplement 1, pp. S31-S33, 2008. 
[106] C. Liao, M. I. Zimmer, S. Shanmuganad, H. Yu, S. L. Cardell, and C. Wang, "Dysregulation of CD1d-restricted type II natural killer $\mathrm{T}$ cells leads to spontaneous development of colitis in mice," Gastroenterology, vol. 142, no. 2, pp. 326-334, 2012.

[107] T. Olszak, D. An, S. Zeissig et al., "Microbial exposure during early life has persistent effects on natural killer T cell function," Science, vol. 336, no. 6080, pp. 489-493, 2012.

[108] G. Wingender, D. Stepniak, P. Krebs et al., "Intestinal microbes affect phenotypes and functions of invariant natural killer $\mathrm{T}$ cells in mice," Gastroenterology, vol. 143, no. 2, pp. 418-428, 2012.

[109] A. Terashima, H. Watarai, S. Inoue et al., "A novel subset of mouse NKT cells bearing the IL-17 receptor B responds to IL-25 and contributes to airway hyperreactivity," Journal of Experimental Medicine, vol. 205, no. 12, pp. 2727-2733, 2008.

[110] A. Camelo, J. L. Barlow, L. F. Drynan et al., "Blocking IL25 signalling protects against gut inflammation in a type-2 model of colitis by suppressing nuocyte and NKT derived IL-13," Journal of Gastroenterology, vol. 47, no. 11, pp. 1198-1211, 2012.

[111] S. A. Gorski, Y. S. Hahn, and T. J. Braciale, "Group 2 innate lymphoid cell production of IL-5 is regulated by NKT cells during influenza virus infection," PLoS Pathogogens, vol. 9, Article ID e1003615, 2013. 


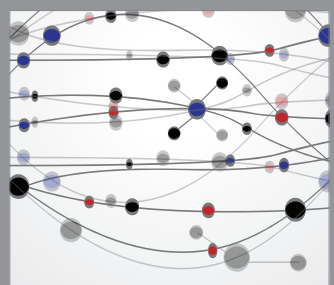

The Scientific World Journal
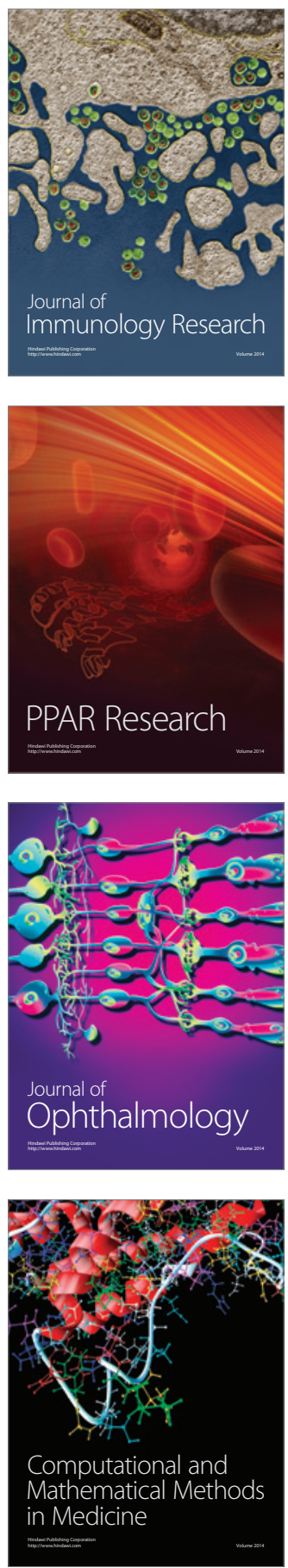

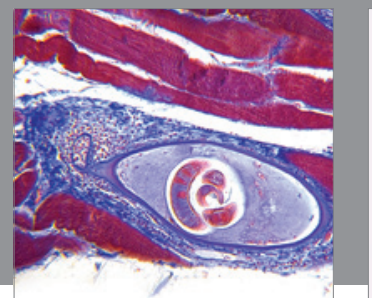

Gastroenterology

Research and Practice
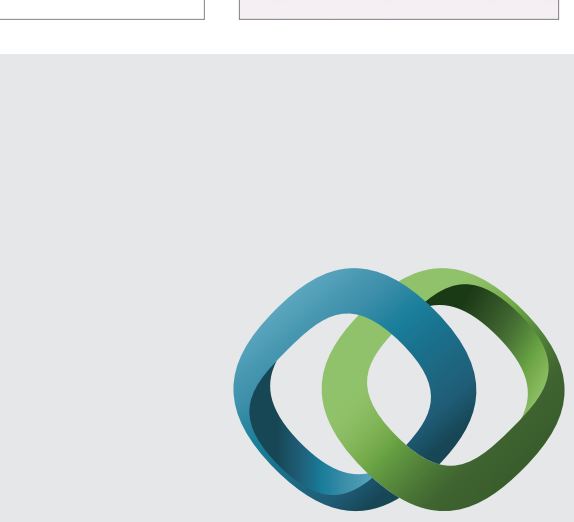

\section{Hindawi}

Submit your manuscripts at

http://www.hindawi.com
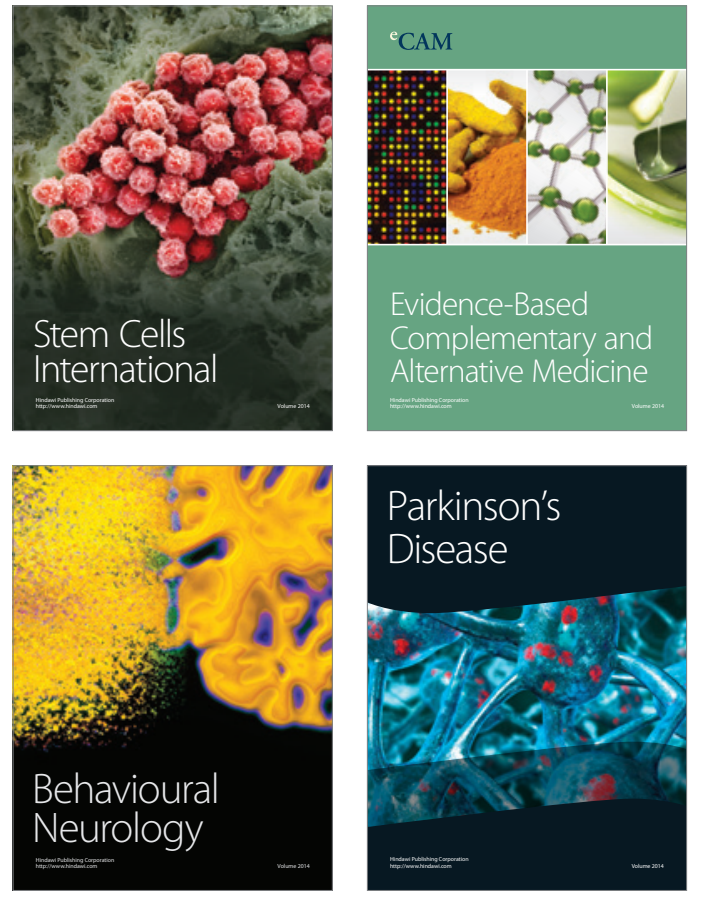
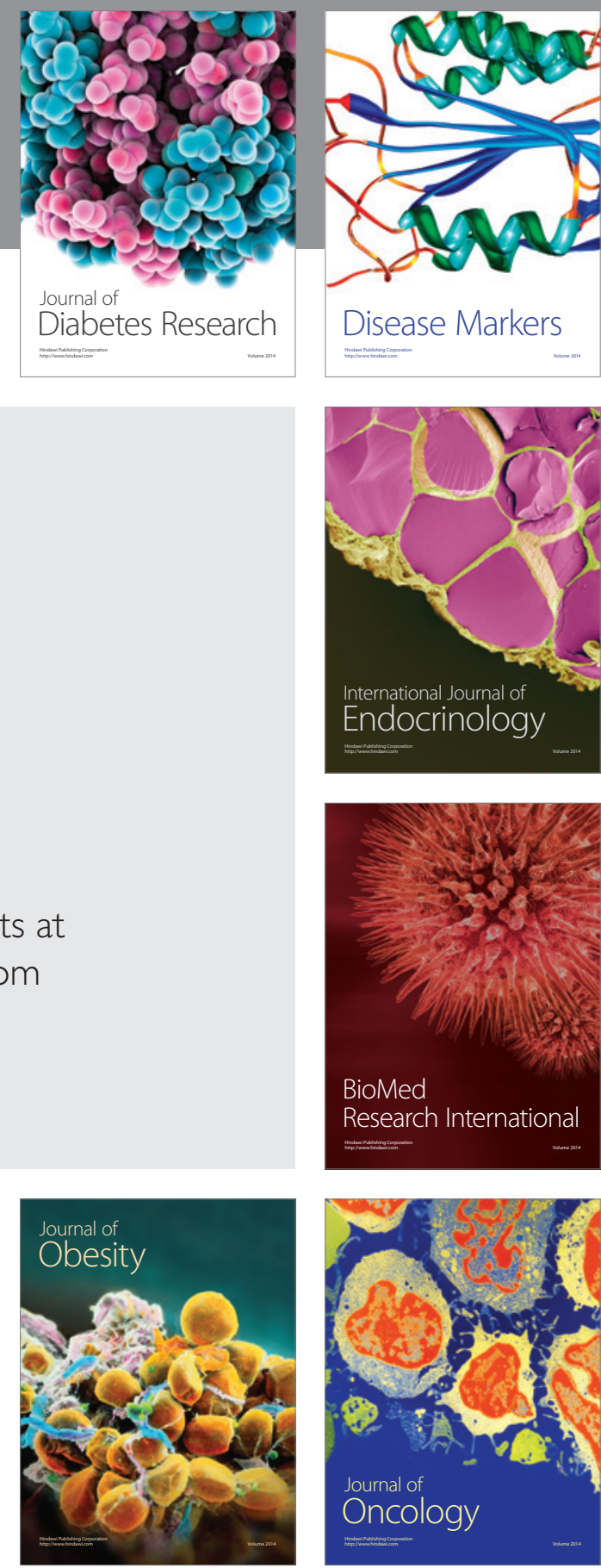

Disease Markers
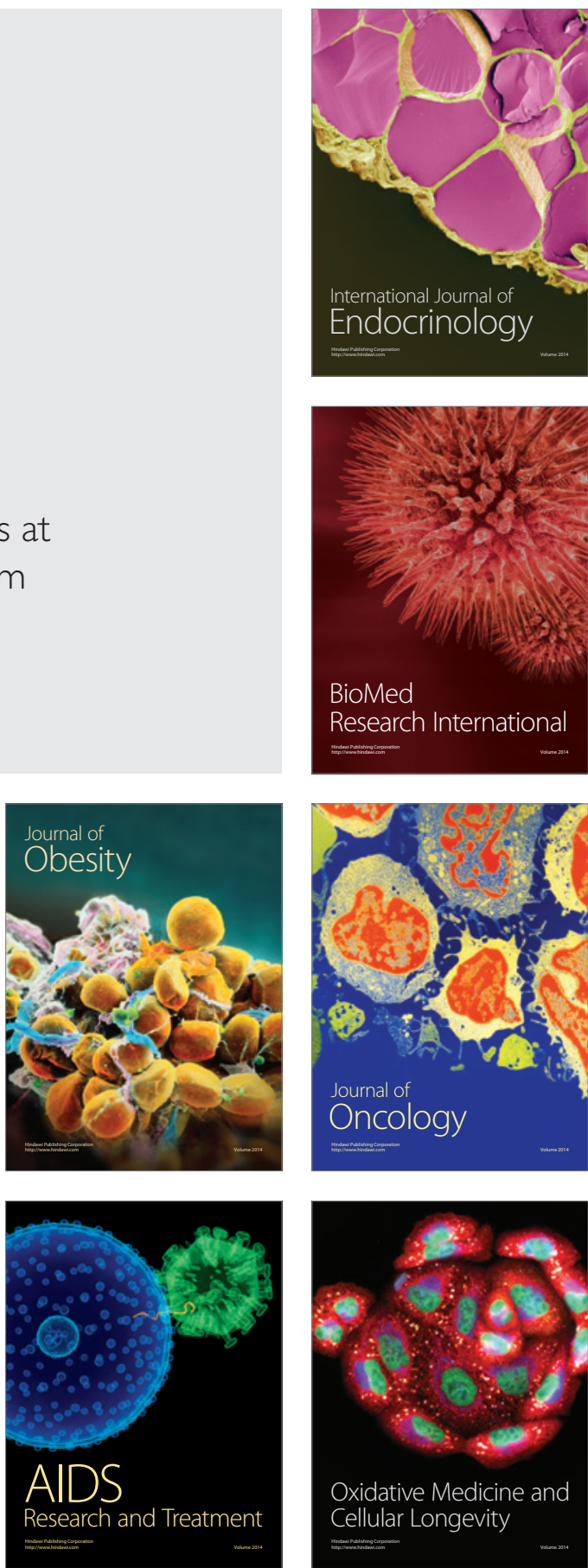